\title{
The role of macroeconomic instability in public and private capital accumulation and growth: the case of Turkey 1963-1999
}

\section{Mustafa Ismihan, Kivilcim Metin-Ozcan \& Aysit Tansel}

To cite this article: Mustafa Ismihan, Kivilcim Metin-Ozcan \& Aysit Tansel (2005) The role of macroeconomic instability in public and private capital accumulation and growth: the case of Turkey 1963-1999, Applied Economics, 37:2, 239-251, DOI: 10.1080/0003684042000286115

To link to this article: http://dx.doi.org/10.1080/0003684042000286115

曲 Published online: 16 Aug 2006.

Submit your article to this journal $\pi$

Џ Article views: 129

Q View related articles $\longleftarrow$

Citing articles: 9 View citing articles 5 


\title{
The role of macroeconomic instability in public and private capital accumulation and growth: the case of Turkey 1963-1999
}

\author{
Mustafa Ismihan $^{\mathrm{a} *}$, Kivilcim Metin-Ozcan ${ }^{\mathrm{b}}$ and Aysit Tansel ${ }^{\mathrm{c}}$ \\ a Atilim University, Kizilcasar Koyu, 06836, Incek-Golbasi, Ankara, Turkey; \\ ${ }^{\mathrm{b}}$ Bilkent University, 06800 Bilkent, Ankara, Turkey and \\ ${ }^{\mathrm{c}}$ Middle East Technical University (METU)
}

This study investigates the empirical relationship(s) between macroeconomic instability, public and private capital accumulation and growth in Turkey over the period 1963-1999. Time series econometric techniques, such as cointegration and impulse response analysis, are used. The results of this paper suggest that the chronic and increasing macroeconomic instability of the Turkish economy has seriously affected her capital formation and growth. Furthermore, the Turkish experience indicates that chronic macroeconomic instability seems to be a serious impediment to public investment, especially to its infrastructural component, and shatters, or even reverses, the complementarity between public and private investment in the long run.

\section{Introduction}

Turkey and many other developing countries, such as those in Latin America, experienced chronic macroeconomic instability by following unstable economic policies, such as populist and myopic macroeconomic policies, over extended periods of time. ${ }^{1,2}$ During their chronic instability episodes the typical developing country tends to exhibit excessive and persistent budget deficit, high debt to GNP ratio and high inflation rate.
Most of the countries suffering from chronic macroeconomic instability register low and volatile rates of capital formation and economic growth. Furthermore, they tend to exhibit low level of public capital spending ${ }^{3}$ as a share of output. Many economists nowadays believe that macroeconomic instability ${ }^{4}$ is detrimental to capital accumulation and economic growth, and there is empirical evidence that supports this view. ${ }^{5}$ Theoretical arguments in this line of research focused on the detrimental effects of macroeconomic instability on private investment

* Corresponding author. E-mail: ismihan@atilim.edu.tr

${ }^{1}$ Recently new political economy literature has emphasized the role of political factors, such as political instability and polarization, on macroeconomic instability. See Drazen (2000) and Persson and Tabellini (2000) for an overview.

${ }^{2}$ Developing countries may also experience macroeconomic instability as a result of structural characteristics such as vulnerability to external shocks.

${ }^{3}$ We will use the terms 'public capital spending' and 'public investment' interchangeably throughout this study.

${ }^{4}$ We define macroeconomic instability in line with Fischer (1993a, 1993b) and Bleaney (1996). A rise in macroeconomic instability means a rise in one or more policy-induced macroeconomic instability indicators, such as inflation rate, public deficit to GNP ratio and external debt to GNP ratio.

${ }^{5}$ See, for example, Fischer (1993a, 1993b), Cardosa (1993) and Bleaney (1996) among others. 
and productivity. ${ }^{6}$ Moreover, early empirical studies, which assessed the effects of macroeconomic instability on investment, used either aggregate investment (Bleaney, 1996) or private investment data (Cardosa, 1993) in their analyses.

Macroeconomic instability has negative effects on both private and public investment, albeit through different channels. While the rise in macroeconomic uncertainty is the main cause for a reduction in private investment, the reduction in the fiscal (as well as political) 'ability' of the government is the principal reason for the decrease in public investment. That is, a rise in the level of macroeconomic instability leads to (or aggravates) fiscal stringency due to the existence of the budget constraint of the government. For example, high inflation rate and/or excessive debt accumulation lowers the overall public resources otherwise available for public expenditures, namely capital and current expenditures. ${ }^{7}$ In turn, the incumbent government lowers public capital expenditures rather than current expenditures when faced with fiscal stringency since it is politically easer to cut the former than the latter. ${ }^{8}$

Many recent empirical studies found positive effects of public capital spending, particularly infrastructural spending, on private investment, productivity and growth. ${ }^{9}$ These studies suggest that a decrease in public capital spending can be harmful for economic growth. More importantly, given the detrimental effects of macroeconomic instability on public investment, these studies imply that chronic macroeconomic instability can be very costly in terms of private capital accumulation and hence economic growth if public and private investment are complementary (i.e. if public investment crowds-in private investment). Thus there seems to be an additional link between macroeconomic instability and economic growth due to the possible complementarity between public and private investment.

Currently there are two related strands of research on the role of public capital spending in capital accumulation and economic growth. The first one focuses on the public capital spending and private investment nexus. In this research area, many studies found significant complementarity (crowding-in) effect, but some studies were either inconclusive or found contradictory results. ${ }^{10}$ Blejer and Khan (1984) among others suggest that this ambiguity might be the result of using aggregate rather than disaggregate public investment data, e.g. public investment in infrastructure. The evidence for the Turkish economy is also ambiguous (see, for example, Anand et al., 1990; Celasun and Tansel, 1993; Conway, 1990; MetinOzcan et al., 2001 and Uygur, 1995). The second approach analyses the public capital spending and output (or growth) nexus. In this approach, the role of public capital spending, especially, infrastructural investment, is theoretically considered both in a production function framework (Aschauer, 1989a) and in a new growth theory framework (Barro, 1990). Considerable number of empirical studies, using either a single-equation time series (Aschauer, 1989a) or a cross-section analysis (Easterly and Rebelo, 1993) have found a positive effect of (infrastructural) public investment on growth.

Nevertheless, early studies in these two groups of literature were criticized on the empirical grounds. The main empirical criticisms are related to the reverse-causation, simultaneity, and 'spuriousness' of the results (Sturm et al., 1998; Pereira, 2000). To overcome these empirical problems, recent studies used new time series techniques, such as multivariate cointegration and impulse response analyses (Ghali, 1998; Pereira, 2000; Mittnik and Neumann, 2001). ${ }^{11}$

\footnotetext{
${ }^{6}$ For instance, it is widely argued that macroeconomic instability adversely affects the rates of productivity growth and investment mainly by creating uncertainty about current and future macroeconomic environment. See, for example, Fischer (1993b) and Bleaney (1996).

${ }^{7}$ On the one hand, a rise in inflation rate usually rises the degree of dollarization and results in a loss of seigniorage revenue, by reducing the demand for domestic currency. Furthermore, high inflation rate will also lower the revenues from ordinary taxes due to the Olivera-Tanzi effect. On the other hand, high indebtedness leads to a high debt burden (principal plus interest payment) and lowers the overall public resources available for other public expenditures. See, for example, Agenor and Montiel (1996) for more detail.

${ }^{8}$ This view is widely shared by many economists and there is empirical evidence that supports it. See De Haan et al. (1996) for an overview and empirical evidence.

${ }^{9}$ See, for example, Sturm et al. (1998), Pereira (2000) and Mittnik and Neumann (2001).

${ }^{10}$ One of the earlier studies in the crowding-in, or more broadly, public capital spending-private investment nexus literature is the work of Blejer and Khan (1984); however, this literature has exploded with the seminal work of Aschauer (1989b). See Agenor and Montiel (1996) for an overview of earlier evidence for the developing countries.

${ }^{11}$ Private investment, public investment and output were the commonly used variables in their analyses of the effects of public capital spending on private capital spending and output.
} 
In this study we are mainly interested in the empirical assessment of the effects of macroeconomic instability on public and private investment as well as in the nature of their relationships (e.g. complementarity) and economic growth. Therefore we extend the recent literature, on the role of public capital spending in capital accumulation and economic growth, to include the issue of macroeconomic instability. We consider the Turkish experience in our study, which we believe is a good case study since Turkey has been suffering from chronic macroeconomic instability over the last 25 years. To accomplish this we estimate the long-run relationship between public investment, private investment, macroeconomic instability and output in Turkey for the period 1963-1999 by using multivariate cointegration analysis. The empirical analysis is also extended by considering the infrastructural component of public investment. Furthermore, the generalized impulse response functions are used to examine the dynamic effects of a rise in (i.e. a shock on) a given variable on all the other variables in the system. We are particularly interested in the analysis of the dynamic effects of an increase in public investment and macroeconomic instability, respectively, on all the other variables.

This paper is organized as follows. Section II provides a condensed overview of macroeconomic instability, capital formation and growth in the Turkish economy over the sample period (19631999). Empirical results appear in Section III and finally Section IV provides a summary and the policy implications of the findings.

\section{An Overview of Macroeconomic Instability, Capital Formation and Growth in the Turkish Economy, 1963-1999}

In this section, we provide a condensed overview of the Turkish economy for the 1963-1999 period. In line with the aims of this paper, we will mainly focus on capital formation, growth and macroeconomic instability. ${ }^{12}$

Table 1 provides summary information on the Turkish economy for the whole (1963-1999) and
Table 1. Selected indicators of the Turkish economy, 1963-1999

$1963-99 \quad 1963-79 \quad 1980-99$

I. Output and capital formation

I.A Annual average growth rate*

Real private fixed investment

Real public fixed investment

Real public fixed core

5.1

4.2

infrastructural investment

Real public fixed non-core

$\begin{array}{lll}5.9 & 10.8 & 2.7\end{array}$

infrastructural investment

I.B Composition of public investment**

Core infrastructural

50.5

investment (as \% of total)

Non-core infrastructural

55.6

investment (as \% of total)

II. Macroeconomic instability**

Macroeconomic instability

0.326

0.514

index (MII)

Inflation rate, $* * * \%$

$41.7 \quad 18.1$

61.8

* Annual average growth rate of variable $X$ (e.g. real GNP) is calculated by using the following formula: Annual average growth rate of $X(\%)=\left(\left(X_{t+n} / X_{t}\right)^{1 / n}-1\right) * 100$, where $X_{t}=$ the value of $X$ in year $t$ (initial year), $X_{t+n}=$ value of $X$ in year $t+n$ (final year) and $n=$ no of 'periods' (years).

** Simple period average.

*** Percentage change in GNP deflator.

Source: See the data appendix

two sub-periods, namely, the inward-oriented period (1963-1979) and the outward-oriented period (19801999). During the 1963-1979 period, Turkey followed a state-led inward-oriented growth strategy by following import substitution policies and economywide planning by the State Planning Organization (SPO). Besides the trade restrictions and financial repression policies (e.g. regulated interest rates), the state made use of heavy public investment, especially in the manufacturing sector, to promote industrialization and economic development.

During the inward-oriented period, Turkey enjoyed a high rate of growth (real GNP grew at an annual average rate of $5.1 \%$ ) and a rapid rate of capita accumulation. While real private investment ${ }^{13}$ increased at an average annual rate of $7 \%$, public investment increased at an average annual rate of $9.7 \%$.

\footnotetext{
${ }^{12}$ See, for example, Aricanli and Rodrik (1990), Celasun and Rodrik (1989), Ekinci (1990, 2000), Metin-Ozcan et al. (2001) and Ozatay (1999) among others for more detailed analyses and discussions on these and related issues on the Turkish economy.

${ }^{13}$ It should be noted that investment series have been revised several times in Turkey during the last two decades (see, for example, Conway, 1990). We reported our results in this section and elsewhere based upon the most recent series of the SPO (see the data appendix for more detail).
} 
During the 1960s the macroeconomic environment was quite stable. ${ }^{14}$ However, mainly due to foreign exchange difficulties of the late 1960s, in 1970 Turkey introduced an IMF-based stabilization package, which involved a maxi devaluation. From 1973 to 1977, Turkey experienced an unprecedented growth in investment, led by public sector investment, mainly in manufacturing and transportation. Both public and private investment grew at high rates of $20.4 \%$ and $8.4 \%$, respectively, during this period. However, macroeconomic instability significantly increased during the mid-1970s mainly due to the deterioration of the fiscal balances and the excessive reliance on foreign borrowing. By the late 1970s Turkey reached a state where it could no longer service even the short-term debts and experienced severe economic crisis.

In 1980, Turkey took a crucial decision to switch its overall economic strategy from inward-oriented growth to outward-oriented growth. The 1980 programme had both stabilization and structural aspects (e.g. trade and financial liberalization), and was strongly backed by IMF, World Bank and OECD consortium. The role of state has crucially changed with this programme; for example, the state changed its investment strategy from manufacturing to infrastructure. During the outward-oriented period of 1980-1999, real GNP of the Turkish economy grew at an average annual rate of $4.2 \%$. Compared to the inward-oriented period, this performance doesn't seem impressive. Furthermore, real GNP fluctuated less during the inward-oriented period compared to the outward-oriented period. Nevertheless, the economic growth rate was higher during the $1980 \mathrm{~s}(5.2 \%$ per year) compared to the $1990 \mathrm{~s}$ (3.2\% per year). Private sector's capital formation performance was better compared to public sector's during the outward-oriented period. Real private (public) investment grew at an average annual rate of $6.1 \%$ (1.6\%), from 1980 to 1999. As we mentioned before, the crucial change in this period was the changing role of the state in the investment process. The share of core public infrastructural (transport + communication + energy) investment in total public investment rose from $37.3 \%$ in the inward-oriented period to $50.5 \%$ in the outward-oriented period. Nevertheless, while private investment-GNP ratio (in current prices) rose from $12.8 \%$ in the 1980 s to $18.1 \%$ in the 1990 s, public investment-GNP ratio dropped from $8.8 \%$ in the 1980 s to $6.2 \%$ in the 1990 s. The main reason behind this fall is the rising macroeconomic instability after the late 1980s, which has seriously lowered the fiscal and political 'ability' of governments for making necessary investments, especially infrastructural investments, due to budgetary pressures. $^{15}$

Generally speaking, macroeconomic instability has steadily increased since the mid-1970s and has become a chronic problem for the Turkish economy. During the early 1980s Turkey was successful in lowering the macroeconomic instability inherited from the economic crisis of the late 1970s. Inflation rate and macroeconomic instability index (MII) fell from $89.6 \%$ and 0.520 points in 1980 to $26 \%$ and 0.317 points in 1983, respectively. Similarly, macroeconomic management was quite good during the mid-1980s. However, starting from the late 1980s macroeconomic instability rose again, mainly due to the political factors (e.g. political instability and polarization) and related populist and myopic policies, ${ }^{16}$ and associated problems of public sector imbalances. Until late 1993, Turkey had managed to maintain the populist and myopic policies mainly with the help of capital inflows. ${ }^{17}$ However, the cost of this strategy was very high, real interest rate on domestic debt had increased steadily during the early 1990s and this further deteriorated the fiscal balances; for instance, domestic interest payments out of consolidated budget (as a percentage of GNP) almost doubled from 1990 to 1993.

Turkey experienced a very severe financial crisis in early 1994 mainly due to unsustainable fiscal balances, the collapse of the domestic debt market, monetization and the expectations of further monetization. Real GNP contracted by $6.1 \%$ during 1994 , which is the peak rate of contraction of the Turkish economy over the 1963-1999 period. Similarly, real public investment fell dramatically by about $40 \%$, from 1993 to 1994. This is a solid evidence of the negative effect of macroeconomic instability on fiscal 'ability' of governments for making investment. Real private investment, however, contracted only moderately (about 5\%). Both inflation and MII peaked

\footnotetext{
${ }^{14}$ During the 1960 s average inflation rate was only $5.2 \%$ compared to the 1970 s $(27 \%)$, the 1980 s $(50.4 \%)$ and the 1990 s $(73.2 \%)$. Furthermore, macroeconomic instability index was 0.04 points and it was the lowest decade average compared to other decades (see the data appendix for more detail on macroeconomic instability index).

${ }^{15}$ In line with this argument, Conway (1990:82) stated that '[r]eal public investment growth appears to have [negatively] responded to budgetary pressures' in Turkey.

${ }^{16}$ See, for example, Ozatay (1999) and Akyurek (1999) for more detail and empirical evidence.

${ }^{17}$ Turkish Lira became fully convertible and capital account was fully-liberalized in 1989.
} 


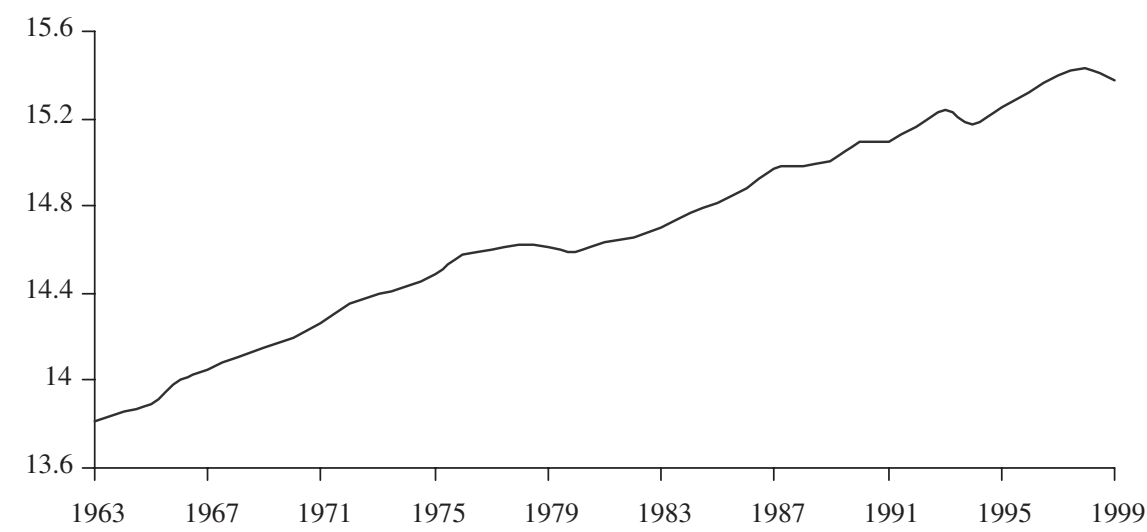

Fig. 1. Time plot of the logarithm of real GNP $(y)$, 1963-1999

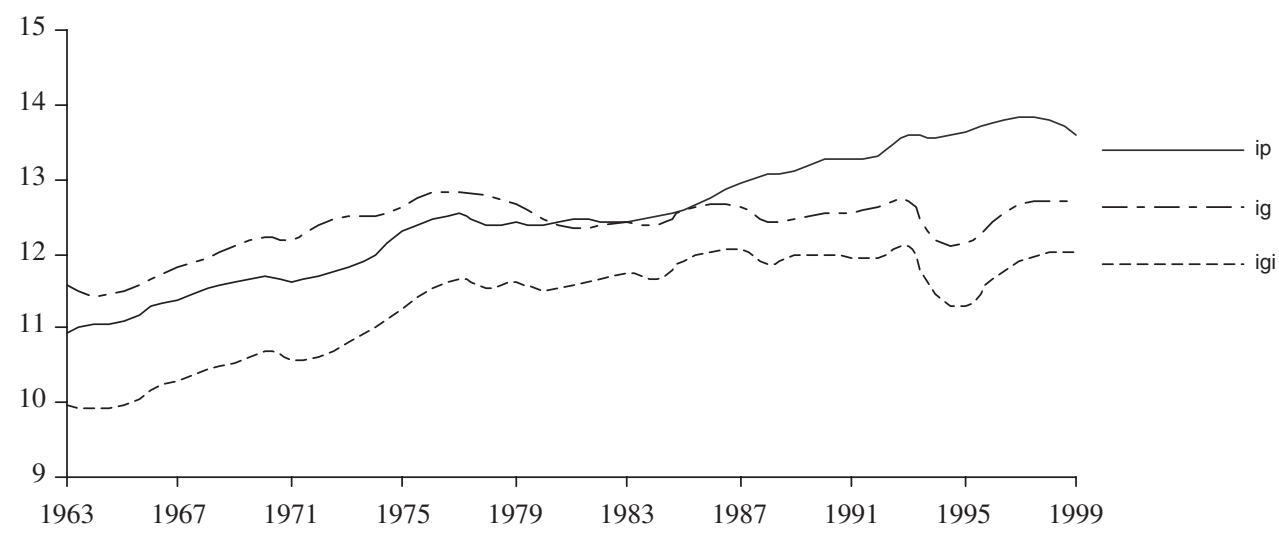

Fig. 2. Time plots of the logarithms of real fixed private investment (ip), real fixed public investment (ig) and real fixed public core infrastructural investment (igi), 1963-1999

in 1994, inflation rate was $107.3 \%$ and MII was 0.842 points in 1994. Furthermore, Turkish Lira depreciated by more than $150 \%$ against US\$ in 1994. In mid-1994, Turkey adopted an IMF-based stand-by agreement, and managed to cool-down the severe economic crisis. Inflation rate and MII fell from $107.3 \%$ and 0.842 points in 1994 to $87.2 \%$ and 0.563 points in 1995, respectively. However, macroeconomic instability has continued until the late 1990s, mainly due to reluctance of governments (e.g. to avoid negative political consequences) to take the necessary painful measures; in other words, governments delayed stabilization. ${ }^{18}$ During this period, public sector balances were unsustainable due to reliance on the domestic borrowing (e.g. real interest rate on domestic debt almost doubled from 1994 to 1999). In December 1999, Turkey signed a three-year IMF-based stand-by agreement, which mainly aimed to solve the public sector imbalances. ${ }^{19}$
Unfortunately, this programme had failed in early 2001 due to a major economic crisis (real GNP contracted by $9.4 \%$ during 2001) and Turkey signed another programme backed by the IMF and the World Bank, which is still being implemented today.

\section{Empirical Results}

\section{Data and unit root tests}

The data used in this study are Turkish annual data from 1963 to 1999 . The sample period is determined by the availability of official investment data. Figures 1-3 show the time plots of the logarithms of real GNP $(y)$, real private fixed investment (ip), real public fixed investment (ig), real public fixed core infrastructural investment (igi) and macroeconomic instability index (mii). The data appendix provides

\footnotetext{
${ }^{18}$ See, for example, Veiga (2000) for well-documented reasons for delayed stabilizations.

${ }^{19}$ See Ekinci (2000) and the references therein for a thorough overview of these problems and extensive assessment of the aspects of this program.
} 


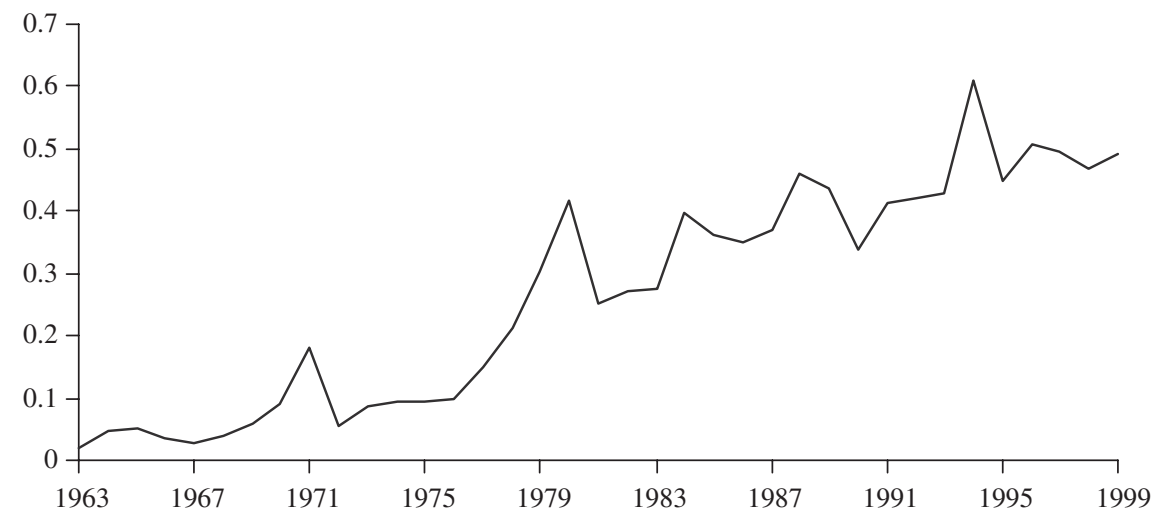

Fig. 3. Time plot of the logarithm of macroeconomic instability index (mii), 1963-1999

Table 2. Unit root tests

\begin{tabular}{|c|c|c|c|c|}
\hline \multirow[b]{3}{*}{ Variables } & \multicolumn{3}{|l|}{ ADF test } & \multirow{3}{*}{$\begin{array}{l}\text { Perron test } \\
\text { Innovation } \\
\text { outlier }_{\text {model }^{\mathrm{f}}}\end{array}$} \\
\hline & \multicolumn{2}{|l|}{ Level } & \multirow{2}{*}{ 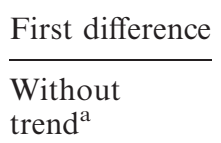 } & \\
\hline & $\begin{array}{l}\text { Without } \\
\text { trend }^{\mathrm{a}}\end{array}$ & $\begin{array}{l}\text { With } \\
\text { trend }^{\text {b }}\end{array}$ & & \\
\hline$y$ & $-1.0696(0)^{\mathrm{c}}$ & $-2.4769(0)$ & $-4.9665(0)^{* \mathrm{~d}}$ & $-2.6439(0)^{\mathrm{h}}$ \\
\hline ip & $-1.2921(1)$ & $-3.0168(3)$ & $-3.3808(0)^{*}$ & $-2.0148(1)$ \\
\hline ig & $-2.2886(3)$ & $-2.4310(1)$ & $-4.5756(0)^{*}$ & $-4.4852(2)^{\mathrm{g}}$ \\
\hline$i g i$ & $-1.9448(0)$ & $-1.8378(0)$ & $-4.4798(1)^{*}$ & $-3.8352(1)$ \\
\hline mii & -1.2578 (1) & $\mathrm{e}^{\mathrm{e}}$ & $-8.0355(0)^{*}$ & $\mathrm{C}^{\mathrm{e}}$ \\
\hline
\end{tabular}

Notes:

${ }^{a}$ ADF regressions include an intercept but not a linear trend (see, Pesaran and Pesaran, 1997, p. 53).

${ }^{\mathrm{b}}$ ADF regressions include both an intercept and a linear trend (see, Pesaran and Pesaran 1997, p. 53).

${ }^{\mathrm{c}}$ Numbers in parentheses are the order of augmentations $\left(p^{*}\right)$ chosen by the Akaike Information Criterion (AIC). Note that unit root test results also hold when $p^{*}(\mathrm{~s})$ are chosen by Schwarz Bayesian Criterion (SBC). Due to a size-power trade-off in the determination of the order of augmentation $(p)$ of ADF tests, we choose to select $\mathrm{p}^{*}$ by AIC, which is a common practice in the applied works (see, Pesaran and Pesaran, 1997, p. 213). Therefore, in line with Pesaran and Pesaran (1997:213), first we estimated ADF regressions for $p=0$ to $p=4$ and selected the order of augmentation $\left(p^{*}\right)$ based on AIC. Then, we performed the ADF tests (see the text). Note that the same sample period (1969-1999) is used in calculations.

${ }^{\mathrm{d}}$ An asterisk (*) represents the rejection of the unit root null hypothesis at the $95 \%$ level (MacKinnon, 1991, Table 1).

${ }^{\mathrm{e}}$ Since MII is bounded between 0 and 1 due to its construction (see the data appendix), we did not include trend for mii (see, for example, Ahmet and Rogers, 2000). Furthermore, linear trend in mii is not meaningful from the economic point of view.

${ }^{\mathrm{f}}$ This model is within innovation outlier framework and allows for both a change in the level and trend (see, Franses, 1998, p. 150-1, for this test).

${ }^{\mathrm{g}}$ ig rejects the null hypothesis at the $95 \%$ level but not at the $99 \%$ level (see Franses, 1998, Table 6.6, for critical values).

${ }^{\mathrm{h}}$ Numbers in parentheses are the order of augmentations $\left(p^{*}\right)$ chosen by the Akaike Information Criterion (AIC). Note that test results also hold when $p^{*}(\mathrm{~s})$ are chosen by Schwarz Bayesian Criterion (SBC) or if we just use the same $p^{*}(\mathrm{~s})$ of the third column. We use the same procedure as in note (c) for determining the order of augmentation $\left(p^{*}\right)$. Note that the same sample period (1969-1999) is used in calculations.

the details on the definitions and the sources of the data.

Visual inspection of the data suggests that all these series have a unit root(s). However, we also provide the formal unit root test results in Table 2. As expected, for all the variables the null hypothesis of a unit root are not rejected at the 95\% level. Furthermore, the null hypothesis of a unit root for the first differences of all variables are rejected at the $95 \%$ level. Therefore, all the variables under consideration are integrated of order 1 . However, it is well-documented that if we neglect the level and/or the trend shift (e.g. due to a structural break) in the unit root tests we could possibly obtain 'spurious' unit root results (Franses, 1998). Therefore, since we know the break date quite well from the evidence 
reported in Section II, which is 1980, we also performed a Perron test, which allows for a change in the level and the trend. As can be seen from Table 2 all variables except ig cannot reject the null hypothesis of a unit root at the $95 \%$ level. However, ig cannot reject the null at the $99 \%$ level. We conclude that all the variables are integrated of order 1 , which is a pre-condition for the cointegration analysis.

\section{Cointegration analysis}

This section provides the cointegration analysis for investigating the long-run relationship(s) between public investment, private investment, macroeconomic instability and output in Turkey over the period 1963-1999. We provide results for total public investment and its infrastructural components. In line with this, we form two cointegration systems: System $1[i p, y, i g, m i i]$ and System $2[i p, y, i g i, m i i]$.

We used the Johansen multivariate technique in our cointegration analyses (Johansen, 1988). Following Hendry and Juselius (2001) and Pesaran and Smith (1998) among others, we first performed a cointegration analysis with constant term entering unrestrictively but with a trend term restricted to lie in the cointegration space. However, the trend term was found to be insignificant in the cointegration relation(s); ${ }^{20}$ hence, following Hendry and Juselius (2001) we performed a cointegration analysis with the constant term entering unrestrictively and without the trend term. Following Juselius (2001) among others, we also included a step (intervention) dummy in each cointegration system to account for the structural break of 1980 . It entered restrictively to the cointegration space. However, this step dummy was found to be insignificant in the cointegration relation. ${ }^{21}$ This might be because the 1980 structural break could have affected several variables similarly ${ }^{22}$ and hence caused the intervention effects to cancel out (Hendry and Juselius, 2001). Therefore, we did not include this dummy variable in our cointegration analysis.

\section{Analysis using total public investment}

First we form the system with variables [ip, $y, i g$, mii] and test for cointegration. Table 3 provides cointegration result for this system with lag length of $\operatorname{VAR}=1 .^{23}$ We also included an impulse dummy for 1994 (D94) unrestrictively in our cointegration analysis. ${ }^{24}$ The trace and max statistics suggest one cointegration relation, ${ }^{25}$ which seems to be the following simple long-run private investment relation: ${ }^{26}$

$$
i p=3.24 y-4.67 m i i-0.29 i g
$$

This equation suggests that private investment is positively affected by output, negatively affected by macroeconomic instability and public investment for the period under study. These results are consistent with theory and the descriptive analysis of the Turkish economy provided in Section II. The standard errors of the cointegration vector in Table 3 show that all variables except ig are statistically significant. We also formally tested the significance of the variables by the exclusion test, which confirm the previous results (Table 3). However, if we consider the cointegration result for System 1 without D94, we have the following simple long-run private investment relation:

$$
i p=3.44 y-5 m i i-0.38 i g
$$

Equations 1 and 2 are quite similar to each other but when we examine standard errors (not reported) all variables seem to be significant in Equation 2.

${ }^{20}$ Underlying trends of the variables under consideration possibly cancelled out in the cointegration relation (Hendry and Juselius, 2001).

${ }^{21}$ Similarly, we also include a step dummy in each cointegration system to account for the effect of the full-financial liberalization in 1989. This step dummy is also found to be insignificant in the cointegration relation.

${ }^{22}$ As can be seen from Figs 1-3, there is some visual evidence on this.

${ }^{23}$ Note that the lag length of the VAR for each system is determined by the Schwarz Bayesian Criterion.

${ }^{24}$ When we examine the regression results for each equation in VAR(1) model, ig equation has non-normal residuals. This is clearly evident in the residual plot of that equation in which 1994 is an outlying observation. (Note that this is consistent with the evidence in Section II.) Therefore, following Hendry and Juselius (2001), we include impulse dummy for 1994 (D94) in our cointegration analysis for System 1. After including D94 in VAR(1) unrestrictively, all equations have normal distributions and none of them show autocorrelation and heteroscedasticity (see Pesaran and Pesaran, 1997 for detailed information on these tests). Due to the same considerations we also include an impulse dummy for 1994 in our cointegration analysis for System 2.

${ }^{25}$ It should be noted here that the trace and max statistics for System 1 without the impulse dummy (D94) also suggest one cointegration relation. Therefore, our results are not an artefact of D94.

${ }^{26}$ Note that this is a simple investment relation since other determinants of investment, such as real interest rate, are absent in Equation 1 due to the purpose of the study, or data availability and/or limitations of cointegrated VAR analysis with relatively small sample size (Pesaran and Pesaran, 1997). 
Table 3. Cointegration analysis of System 1

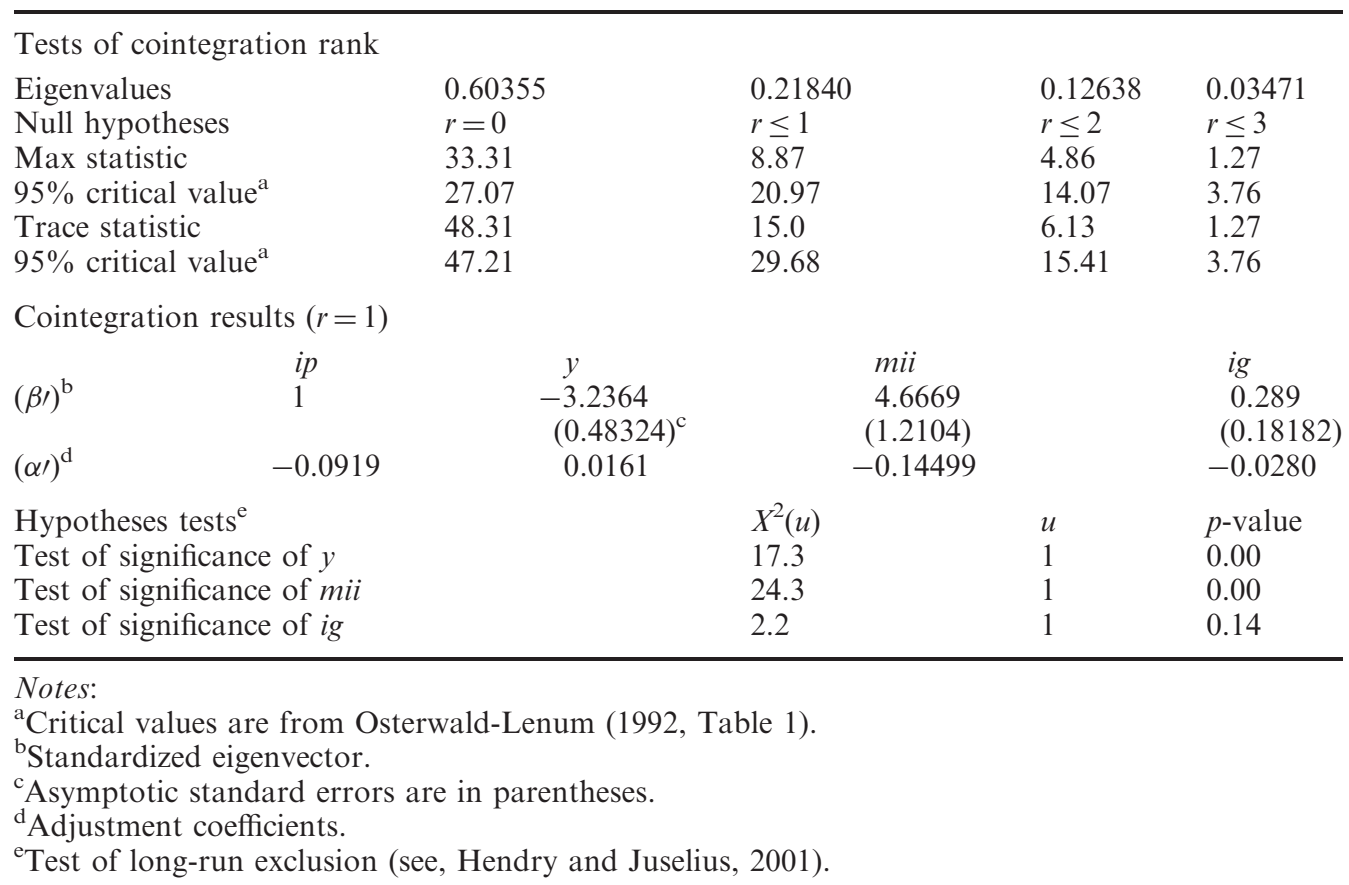

The result of significance (exclusion) test provides a $p$-value of 0.059 for ig ( $y$ and mii both have $p$-value $=0)$; therefore, there is some (but marginal) evidence of long-run crowding-out effect.

\section{Analysis using infrastructural public investment}

We now provide the cointegration analysis for an alternative version by substituting public core infrastructure investment (igi) for total public investment (ig). Table 4 provides the cointegration results for this system with lag length of $\mathrm{VAR}=1 .{ }^{27}$ The evidence favours one cointegration relation and it is also interpreted as the private investment relation. The crucially different result in this system is that even though igi has a negative effect (crowding-out) on ip, its coefficient is not significant, as indicated by the long-run exclusion test. Furthermore, this is also the case without D94. ${ }^{28}$ After imposing the longrun exclusion restriction (and the normalization restriction), the investment relation becomes:

$$
i p=3.15 y-5.20 \mathrm{mii}
$$

This simple investment equation suggests that private investment is positively affected by output and negatively affected by macroeconomic instability. Again, these results are consistent with theory and the descriptive analysis of the Turkish economy provided in Section II.

Finally, we would like to note that our main results in this section also hold when we use inflation rate as a proxy ${ }^{29}$ for macroeconomic instability. This is provided in Ismihan (2003). In the next section, we examine the dynamic effects of a rise in (i.e. a shock on) a given variable on all the other variables in the system, by using impulse response analysis.

\section{Impulse response analysis}

Lutkepohl and Reimers (1992) and Pesaran and Pesaran (1997) among others pointed out the importance of impulse response analysis in cointegrated systems. In this section, we provide the generalized impulse response (IR) functions ${ }^{30}$ to examine the dynamic effects; that is, short- and medium-run effects of a shock on a given variable on all the

\footnotetext{
${ }^{27}$ Due to similar considerations D94 enters unrestrictively to the cointegration analysis.

${ }^{28}$ Note that, in System 2 without D94, the private investment relation becomes: $i p=3.21 y-0.23$ igi -4.45 mii. Furthermore, all variables are significant except igi $(p$-value $=0.11)$.

${ }^{29}$ According to Fischer (1993b:487), inflation rate is the best single indicator [of policy-induced macroeconomic instability] and 'serve as an overall ability of government to manage the economy'.

${ }^{30}$ We prefer to use generalized IR functions since, unlike to the orthogonalized IR functions, the generalized IR functions do not depend on the ordering of the variables within the system (Pesaran and Shin, 1998).
} 
Table 4. Cointegration analysis of System 2

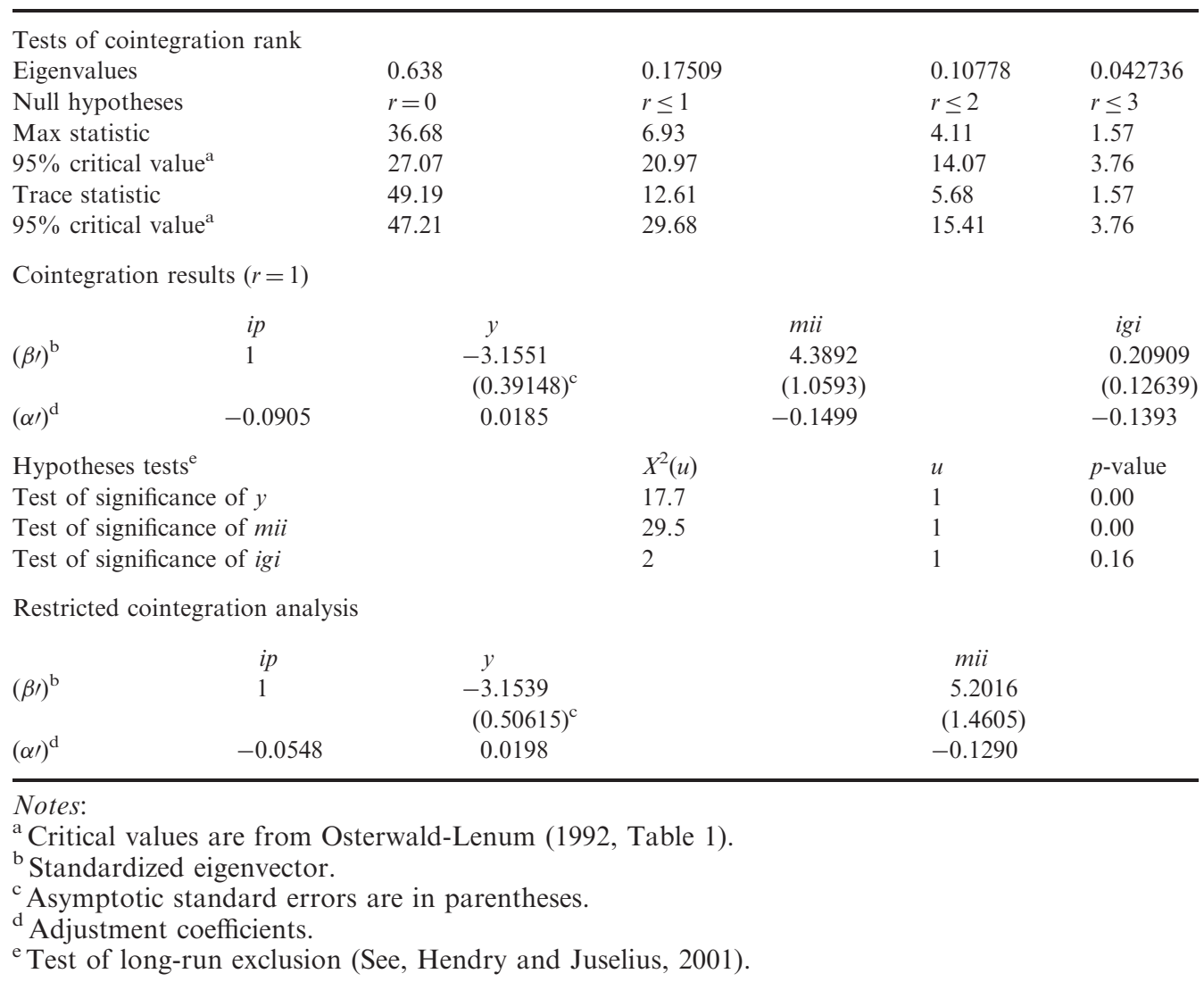

other variables in the system. Below, we present this analysis for the System 1 only since the impulse response analysis of System 2 is quite similar to that of System 1. ${ }^{31}$

In order to assess the dynamic effects of a rise in macroeconomic instability on other variables in the system, we examine the generalized IRs to a positive unit [one standard error (SE)] shock in macroeconomic instability (mii) equation. These generalized IRs are provided in panel (a) of Fig. 4. As expected, short- and medium-run responses are negative. That is, private investment, public investment and output are negatively and permanently affected from a rise in macroeconomic instability. However, the effect on private investment was larger compared to the effect on output. The effect on public investment was also large. This is probably due to a negative effect of a rise in macroeconomic instability on the public resources.
Hence, governments tend to cut public investment rather than current (or populist) spending in the case of fiscal stringency since it is politically easer to cut public investment than current spending. All these results are consistent with our analysis in Section II. Finally, as can be seen from panel (a) of Fig. 4, the impact effects of a rise in macroeconomic instability on both private and public investments are smaller compared to the medium-term effects; that is, the effect of an increase in macroeconomic instability has an accelerating negative effect on investment, especially, on private investment.

We next examine the dynamic effects of a rise in (a positive unit shock to) public investment on other variables in the cointegration system. As can be seen from the panel (b) of Fig. 4, responses of private investment and output are positive; however, the response of the former is much larger. These results

\footnotetext{
${ }^{31}$ There is only one considerable difference. In the System 2, infrastructural public investment is more seriously affected from macroeconomic instability (shock) compared to total public investment in the System 1. This is consistent with the observation that Turkey failed to make necessary infrastructural investment due to the constraining effects of macroeconomic instability (and associated fiscal problems) on the incumbent goverments' budgets during the late 1990s, and hence experienced infrastructural bottlenecks, such as energy bottlenecks, during the late 1990s and the early 2000s. The results of generalized IR analysis for the System 2 can be requested from the first author.
} 
(a) Generalized IR(s) to one S.E. shock in the equation for mii

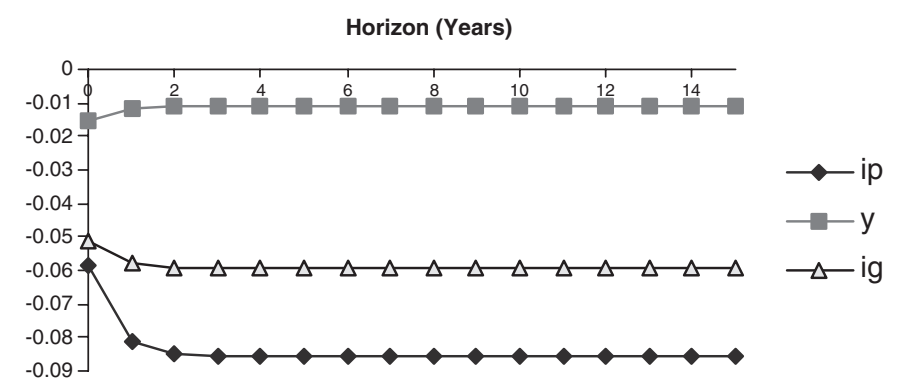

(b) Generalized IR(s) to one S.E. shock in the equation for ig

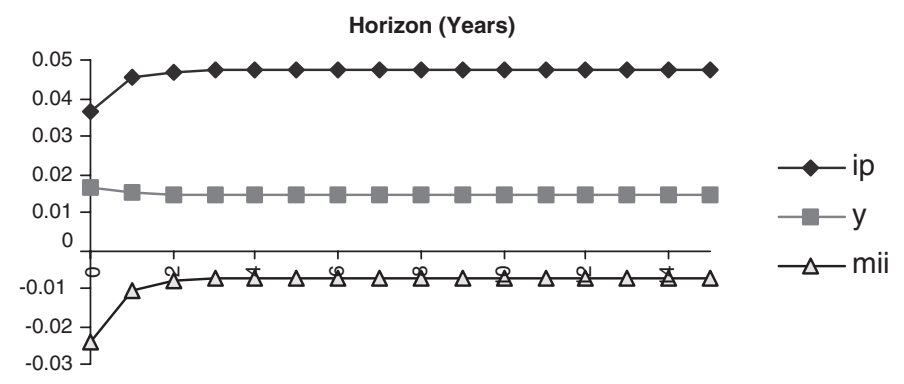

(c) Generalized IR(s) to one S.E. shock in the equation for $y$

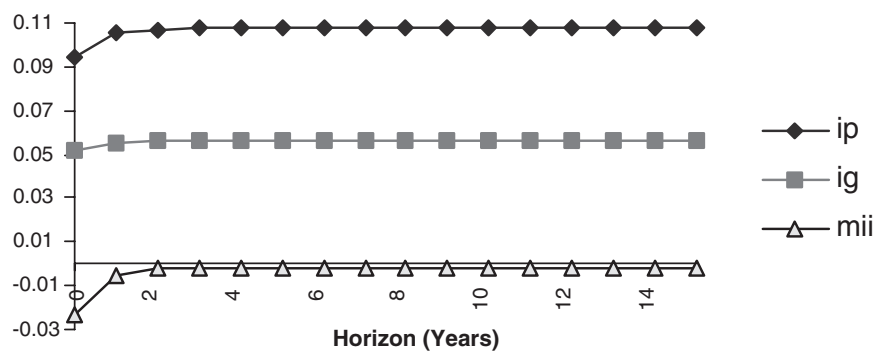

Fig. 4. Generalized IR(s) to one SE shock in the equation for (a) mii, (b) ig, and (c) $y$

suggest a complementarity between public and private investment in the short and the medium-run. Note that, public and private investment moved or 'wandered' together, implying complementarity, until the late 1970s (see Fig. 2) but after the late 1970s this relationship started to shatter possibly due to a negative effect of chronic macroeconomic instability on both private and public investment but via different channels (and with different magnitudes), as we mentioned in the introduction section. Furthermore, this relationship seems to be reversed after the late 1980 s, possibly due to rising macroeconomic instability and associated deterioration in fiscal balances, which has affected both public and private investment. Therefore, in the case of Turkey, chronic and increasing macroeconomic instability and associated fiscal problems seems to shatter or even reverse the complementarity between public and private investment in the long run. ${ }^{32}$

Furthermore, response of macroeconomic instability to a rise in public investment is initially negative but over the medium term it diminishes towards zero. This result suggests that the rise in public investment does not contribute to the macroeconomic instability over the short and the medium term. One potential explanation for this seemingly counterintuitive result is that an increase in public investment in case of chronic macroeconomic instability and associated fiscal stringency signals a decisive change in fiscal policy, e.g. from populist to productive spending, and could have immediate political credibility and expectation effects which will lower expected

\footnotetext{
${ }^{32}$ Metin-Ozcan et al. (2001) pointed out the negative effects of domestic debt financing (due to a rise in interest rates), after 1989, on the crowding-in effects of public investment on private investment and output in Turkey.
} 
inflation, inflation risk on borrowing, and hence macroeconomic instability (see, for example, Alesina et al., 1998; and Perotti, 1999, and the references therein for similar arguments). ${ }^{33}$ Furthermore, public (and also private) investment affects both the demand and the supply-side of the economy. The rise in public investment increases expenditures of government but the rise in public investment also increases national income and output due to its dual role. The rise in national income will, in turn, increase the revenues of government, e.g. tax and seigniorage revenue, and help to reduce the fiscal deficit and inflation over some period, but with diminishing effects.

Finally, we examine the dynamic effects of a rise in (a positive unit shock to) output on all the other variables. As panel (c) of Fig. 4 reveals, the short and the medium-run responses of private investment to a rise in output is positive as expected. Similarly, the response of public investment is also positive. As panel (c) of Fig. 4 makes clear, the impact effects of a rise in output on both private and public investment are only slightly different from medium-term effects. The short-run responses of macroeconomic instability is negative (e.g. due to the positive effect of a rise in output on revenues of government and, hence, on budget deficit and inflation); however over the medium term this response approaches towards zero. ${ }^{34}$

\section{Conclusions and Policy Implications}

This study investigated the empirical relationships between macroeconomic instability, public and private capital accumulation and growth in Turkey over the period 1963-1999. The main conclusion is that the chronic macroeconomic instability of the Turkish economy has seriously affected the capital formation and growth. Even though we found some evidence of crowding-out effect of total public investment on private investment, there was no significant effect of infrastructural public investment on private investment in the long run. However, we found some evidence of complementarity between private and public investment (and with its infrastructural component) over the short and medium-run. Our results suggest that the chronic macroeconomic instability seems to become a serious impediment to the public investment, and has shattered, or even reversed, the long-run complementarity. This result may also shed some light on the ambiguity concerning the empirical evidence on the complementarity (crowding-in) effect for the Turkish economy. Moreover, given the evidence on the short- and medium-term complementarity between public and private investment, these results imply that macroeconomic instability has been very costly in terms of private capital accumulation and economic growth during the chronic instability episode of Turkey.

The policy implications are straightforward when we consider these results. Generally speaking, over the last twenty-five years, governments in Turkey either delayed or did not continue with the stabilization programmes. The barriers to stabilization, such as political instability and polarization, are well documented in Veiga (2000) and Drazen (2000) among others. Nevertheless, as this study shows, macroeconomic instability has an adverse impact on capital accumulation and economic growth in Turkey. Therefore, the government should continue the current stabilization programme to restore macroeconomic stability, as soon as possible. This is the first policy implication. The second policy implication is that policy makers have to be careful in their decisions concerning the components of public spending that would bear the burden of fiscal adjustment in the process of the restoration of macroeconomic stability. If government reduces public capital spending (especially, infrastructural spending) instead of current and populist spending; then, this would harm capital accumulation, economic growth and development. ${ }^{35}$ Furthermore, as opposed to the conventional view that fiscal adjustments are recessionary, there is growing evidence that some types of fiscal adjustments may be expansionary (Perotti, 1999; Alesina et al., 1998). This new line of research argues that composition of adjustment matters. For example, fiscal adjustments based on current spending may be expansionary under certain conditions, such as high level of debt to GNP ratio (Perotti, 1999).

In sum, Turkish experience has shown that macroeconomic instability not only deters economic growth but it may also reverse the complementarity between public and private investment in the long-run. In order to shed more light on this result, this study

\footnotetext{
${ }^{33}$ According to Perotti (1999:1400), '. . in times of fiscal stress the economy's response to fiscal shocks changes qualitatively.'

${ }^{34}$ The dynamic effects of private investment shock are similar to public investment shock on all the other variables (simply replace ip with ig in panel (b) of Fig. 4); therefore, it is not separately explained.

${ }^{35}$ See, for example, World Bank (1994) and the references therein, for the crucial importance and the multi-dimensional roles of infrastructure in economic development.
} 
can be further extended to other developing countries suffering from chronic instability like Turkey and this is left for future research.

\section{Acknowledgements}

This paper is based on Mustafa Ismihan's $\mathrm{PhD}$ thesis (Ismihan, 2003) prepared under the co-supervision of Aysit Tansel and Kivilcim Metin-Ozcan in the Department of Economics, METU. The first author would like to thank Merih Celasun and Nazim Ekinci for helpful comments and discussions. Substantial revisions of this paper were made during Mustafa Ismihan's stay at the University of York as a Visiting Scholar; he thanks the Turkish Academy of Sciences (TUBA) for financial support and the Department of Economics and Related Studies of the University of York for their hospitality. Our special thanks go to Gulcin Ozkan whose comments and discussions have greatly improved this paper. We are also grateful to Karim Abadir, Fikret Senses and Fatma M. Utku-Ismihan for helpful comments. The first draft of this paper was presented in the ERC/METU International Conference in Economics V, in September 2001. We would also like to thank conference participants and, especially Yakup Kepenek, for helpful comments. The usual disclaimers apply.

\section{References}

Agenor, P. R. and Montiel, P. J. (1996) Development Macroeconomics, Princeton University Press, Princeton, NJ.

Ahmed, S. and Rogers, J. (2000) Inflation and the great ratios: long term evidence from the U.S., Journal of Monetary Economics, 45, 3-35.

Akyurek, C. (1999) Fiscal policy, seigniorage, and myopic governments: theory and evidence from Turkey, Yapi Kredi Economic Review, 10(1), 45-61.

Alesina, A., Perotti, R. and Tavares, J. (1998) Political economy of fiscal adjustments, Brookings Papers on Economic Activity, 197-266.

Anand, R., Chhibber, A. and Van Wijnbergen, S. (1990) External balance and growth in Turkey: can they be reconciled?, in The Political Economy of Turkey: Debt, Adjustment, and Sustainability (Eds) T. Aricanli and D. Rodrik, Macmillan, London.

Aricanli, T. and Rodrik, D. (1990) The Political Economy of Turkey: Debt, Adjustment, and Sustainability, Macmillan, London.

Aschauer, D. A. (1989a) Is public expenditure productive?, Journal of Monetary Economics, 23, 177-200.

Aschauer, D. A. (1989b) Does public capital crowd-out private capital?, Journal of Monetary Economics, 24, 171-88.

Barro, R. J. (1990) Government spending in a simple model of endogenous growth, Journal of Political Economy, 98, S103-25.
Bleaney, M. F. (1996) Macroeconomic stability, investment and growth in developing countries, Journal of Development Economics, 48, 461-77.

Blejer, M. I. and Khan, M. S. (1984) Government policy and private investment in developing countries, IMF Staff Papers, 31, 379-403.

Cardosa, E. (1993) Private investment in Latin America, Economic Development and Cultural Change, 41, 833-48.

Celasun, M. and Rodrik, D. (1989) Debt, adjustment and growth: Turkey, in Developing Country Debt and Economic Performance, Country Studies (Eds) J. Sachs and S. M. Collins, University of Chicago Press, Chicago.

Celasun, M. and Tansel, A. (1993) Distributional effects and saving-investment behavior in a liberalizing economy: the case of Turkey, METU Studies in Development, 20, 269-98.

Conway, P. (1990) The record on private investment in Turkey, in The Political Economy of Turkey: Debt, Adjustment, and Sustainability (Eds) T. Aricanli and D. Rodrik, Macmillan, London.

De Haan, J., Sturm, J. E. and Sikken, B. J. (1996) Government capital formation: explaining the decline, Weltwirtschaftliches Archiv, 132(1), 55-74.

Drazen, A. (2000) Political Economy in Macroeconomics, Princeton University Press, Princeton, NJ.

Easterly, W. and Rebelo, S. (1993) Fiscal policy and economic growth: an empirical investigation, Journal of Monetary Economics, 32, 458-93.

Ekinci, N. (1990) Macroeconomic developments in Turkey: 1980-1988, METU Studies in Development, 17(1-2), $73-114$.

Ekinci, N. K. (2000) The IMF and reforming the public sector in Turkey, METU Working Papers in Economics, No. 00/04, METU, Ankara.

Fischer, S. (1993a) Does macroeconomic policy matter? Evidence from developing countries, ICEG Occasional Papers, No. 27.

Fischer, S. (1993b) The role of macroeconomic factors in growth, Journal of Monetary Economics, 32, 485-512.

Franses, P. H. (1998) Time Series Models For Business and Economic Forecasting, Cambridge University Press, Cambridge.

Ghali, K. H. (1998) Public investment and private capital formation in a vector error-correction model of growth, Applied Economics, 30, 837-44.

Hendry, F. D. and Juselius, K. (2001) Explaining cointegration analysis: part II, The Energy Journal, 22(1), 75-120.

Ismihan, M. (2003) The role of politics and instability on public spending dynamics and macroeconomic performance: theory and evidence from Turkey, Unpublished PhD thesis, METU, Ankara, December 2003.

Johansen, S. (1988) Statistical analysis of cointegration vectors, Journal of Economic Dynamics and Control, 12, 231-54.

Juselius, K. (2001) Unit roots and the demand for cigarettes in Turkey: pitfalls and possibilities, Discussion paper, No.01-02, Institute of Economics, University of Copenhagen.

Lutkepohl, H. and Reimers, H. E. (1992) Impulse response analysis in cointegrated systems, Journal of Economic Dynamics and Control, 16(1), 53-78.

MacKinnon, J. G. (1991) Critical values for cointegration tests, in Long-run Economic Relationships: Readings in 
Cointegration (Eds) R. F. Engle and C. W. J. Granger, Oxford University Press, Oxford.

Metin-Ozcan, K., Voyvoda, E. and Yeldan, E. (2001) Dynamics of macroeconomic adjustment in a globalized developing economy: growth, accumulation and distribution, Turkey 1969-1998, Canadian Journal of Development Studies, 22(1), 219-53.

Mittnik, S. and Neumann, T. (2001) Dynamic effects of public investment: vector autoregressive evidence from six industrialized countries, Empirical Economics, 26, 429-46.

Osterwald-Lenum, M. (1992) A note with quantiles of the asymptotic distribution of the maximum likelihood cointegration rank test statistics, Oxford Bulletin of Economics and Statistics, 54(3), 461-71.

Ozatay, F. (1999) Populist policies and the role of economic institutions in the performance of the Turkish economy, Yapi Kredi Economic Review, 10(1), 13-26.

Pereira, A. (2000) Is all public capital created equal?, Review of Economics and Statistics, 82, 513-18.

Perotti, R. (1999) Fiscal policy in good times and bad, Quarterly Journal of Economics, 114, 1399-436.

Persson, T. and Tabellini, G. (2000) Political Economics: Explaining Economic Policy, The MIT Press, Cambridge, MA.

Pesaran, M. H. and Pesaran, B. (1997) Working with Microfit 4.0: Interactive Econometric Analysis, Oxford University Press, Oxford.

Pesaran, M. H. and Shin, Y. (1998) Impulse response analysis in linear multivariate models, Economic Letters, 58, 17-29.

Pesaran, M. H. and Smith, R. P. (1998) Stuctural analysis of cointegrating VARs, Journal of Economic Surveys, 12, 471-505.

State Planning Organization (SPO) (1997) Economic and Social Indicators (1950-1998), SPO, Ankara.

State Planning Organization (SPO) (2001) Main Economic Indicators, May 2001, SPO, Ankara.

Sturm, J., Kuper, G. H. and De Haan J. (1998) Modeling government investment and economic growth on a macro level: a review, in Market Behaviour and Macroeconomic Modelling (Eds) S. Brakman, H. van Ees and S. K. Kuipers, MacMillan, London.

United Nations Development Programme (UNDP) (1992) Human Development Report 1992, UNDP, New York.

Uygur, E. (1995) Recent estimates of investment and private investment behaviour in Turkey, in Investment and The Labour Market in Turkey: Proceedings of $A$ Seminar Held in Ankara 7 December 1995 (Ed.) T. Bulutay, SIS, Ankara.

Veiga, F. J. (2000) Delays of inflation stabilizations, Economics and Politics, 12, 275-95.

World Bank (1994) World Development Report 1994: Infrastructure for Development, Oxford University Press for the World Bank, New York.

\section{Data Appendix}

$y$ is the (natural) logarithm of real GNP in 1994 prices (billion TL).

Source: SPO (1997) and SPO (2001).

ip is the (natural) logarithm of real private fixed investments in 1994 prices (billion TL). Nominal private fixed investment series were deflated by private fixed investment deflator series.

Source: SPO (1997) and SPO (2001). Note: deflators were provided by the SPO.

ig is the (natural) logarithm of real public fixed investments in 1994 prices (billion TL). Nominal public fixed investment series were deflated by public fixed investment deflator series.

Source: SPO (1997) and SPO (2001). Note: deflators were provided by the SPO.

igi is the (natural) logarithm of real public fixed core infrastructural investments in 1994 prices (billion TL). Nominal sectoral public fixed investment series were deflated by relevant sectoral public fixed investment deflator series. In line with Ekinci (1990) among others we define core infrastructural investment as the total of the public energy, transportation and communication sectors' fixed investments. See World Bank (1994:2) for broad definition of infrastructure. Source: SPO (1997) and SPO (2001). Note: Sectoral deflators were provided by the SPO.

mii is the (natural) logarithm of the macroeconomic instability index (MII), i.e. $m i i=\ln (1+\mathrm{MII})$. This index is calculated by using human development index (HDI) methodology (UNDP, 1992) and it is based on macroeconomic instability indicators, such as inflation rate, public deficit to GNP ratio, external debt to GNP ratio and change in exchange rate, identified by previous researchers (see, for example, Fischer, 1993a, 1993b; Bleaney, 1996). It is a simple average of the four sub-indices obtained from these four variables. MII is bounded between 0 and 1 due to its construction. We use this index (MII) as a proxy for macroeconomic instability.

Source: Ismihan (2003). 